\title{
Regression Method of Determining Generalized Description of Flow Curve of Steel under Dynamic Recrystallization
}

\author{
Akira YANAGIDA and Jun YANAGIMOTO \\ Institute of Industrial Science, The University of Tokyo, 4-6-1 Komaba, Meguro, Tokyo 153-8505 Japan.
}

(Received on January 24, 2005; accepted on April 1, 2005)

\begin{abstract}
A regression method of obtaining a generalized description of a flow curve is proposed in this paper. The flow curve of a metal at a constant temperature and a constant strain rate is precisely obtained by an inverse analysis of hot compression. To eliminate the error in the flow curve induced by the inhomogeneous distribution of temperature in the test piece, an electromagnetic analysis of induction heating is performed with thermal analysis throughout the heating and hot compression of a test piece. The coefficients embedded in the flow curve are determined by the inverse analysis associated with thermomechanical FE (Finite Element) analysis. The obtained coefficients, which cover wide ranges of hot-forming temperature and high strain rate, are regressed using the proposed regression method, and a generalized flow curve for a $\mathrm{C}-\mathrm{Si}-\mathrm{Mn}$ steel is obtained. Although the proposed regression method is demonstrated for only one type of C-Si-Mn steel, it could also be used to obtain a generalized description of a flow curve for other types of steel under dynamic recrystallization, which could be used to estimate the force characteristics of hot metals in bulk forming processes, such as forging and rolling.
\end{abstract}

KEY WORDS: generalized flow curve; hot compression test; regression; inverse analysis; dynamic recrystallization.

\section{Introduction}

The flow stress of metals under forming is the most important parameter for research and development of forming technology. Currently, the FE analysis is widely used to calculate the force and deformation characteristics of metals under forming. One of the most important factors that influence the accuracy of solutions is the flow curve used for the FE analysis. Many flow curves have been measured for different types of steel, but most of these flow curves are not formulated as a generalized description, which is a function of strain, strain rate and temperature. ${ }^{1-3)}$ A generalized description of a flow curve is important as it gives us a flow curve for wide ranges of temperature and strain rate in hot forming. Such a flow curve was obtained in previous research studies. ${ }^{4-13)}$ However, a more precise description of a generalized flow curve is desired. Also, the number of generalized flow curves available at present should be increased to cover more types of steel with various alloy compositions that have been forged or rolled.

We have proposed a method of obtaining a flow curve under dynamic recrystallization by inverse analysis. ${ }^{14)}$ In the present research, the electromagnetic analysis of induction heating during heating and a hot compression test is newly introduced in thermomechanical FEM in the inverse analysis, with the aim of realizing a more accurate estimation of the inhomogeneous temperature field of a test piece. From the accurately determined coefficients of the flow curve corresponding to the wide ranges of temperature and strain rate, a method of developing a generalized descrip- tion of a flow curve is presented. Finally, the generalized flow curve for $0.20 \% \mathrm{C}-\mathrm{Si}-\mathrm{Mn}$ steel is presented as an example.

\section{Electromagnetic Analysis of Induction Heating dur- ing Hot Compression Test}

\subsection{Experimental Apparatus}

Figure 1 shows the experimental apparatus of the hot compression test. A high-speed multistage hot compression testing machine is used to obtain the compression force versus stroke curve at the test temperature. The temperature of the test piece is controlled to keep the target test temperature constant by induction heating. The coil for induction heating surrounds the tools and test piece, as shown in Fig. 1. The thermocouple is welded at midheight of the test piece. Using the deviation in measured temperature from the target temperature as an input signal, the electric current of induction heating is controlled by the PID feedback.

Even though the measured temperature is maintained as the target temperature, the temperature of the test piece distributes in the cross section, because radiation, heat transfer to the atmosphere and heat conduction to the tools occur during the preheating to the target temperature and hot compression test. Also, heat generation by the induction heating is not uniform across the cross section of the test piece. A uniaxial flow curve could be obtained by the inverse analysis of hot compression proposed previously. ${ }^{14)}$ As this inverse analysis necessitates an accurate temperature distribution in the test piece, the thermomechanical FE 

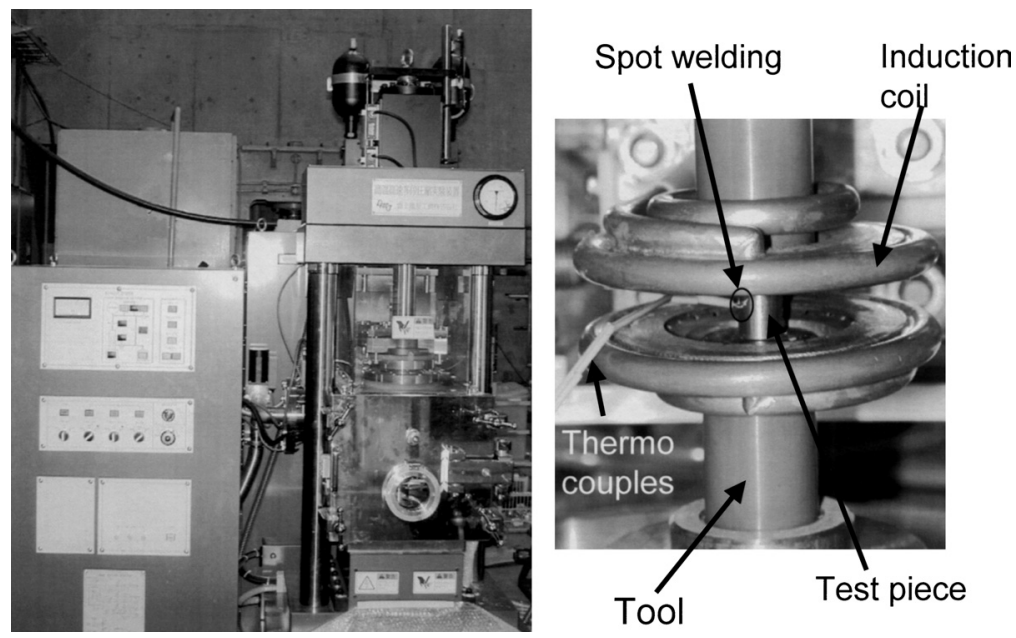

Fig. 1. Experimental apparatus for hot compression test.

analysis of hot compression is implemented in the inverse analysis of the flow curve using the measured change in the compression force versus stroke curve. Previously, ${ }^{14)}$ the empirical relationship was applied to estimate the internal heat generation induced by induction heating, which may have resulted in the error in the flow curve obtained by the inverse analysis. Also, this empirical relationship could not be applied to induction heating during upsetting in a hot compression test.

As the present investigation is aimed at presenting a generalized description of a flow curve, which could be used in the development of forming technologies, we should reduce the error in the flow curve as much as possible. Then, a new electromagnetic analysis of induction heating for estimating the nonuniform generation of internal heat is developed, which is coupled with the thermomechanical analysis of hot compression.

\subsection{Electromagnetic Analysis of Induction Heating}

The magnetic field induced by electric current is governed by Eqs. (1) and (2) for generalized three-dimensional problems. $^{15)}$

$$
\begin{array}{r}
\operatorname{rot}(\boldsymbol{v} \operatorname{rot} \boldsymbol{A})=\mathbf{J}_{0}-\Theta \frac{\partial \boldsymbol{\Lambda}}{\partial t}-\Theta \operatorname{grad} \phi \\
\mathbf{J}_{\mathrm{e}}=-\Theta \frac{\partial \boldsymbol{\Lambda}}{\partial t}-\Theta \operatorname{grad} \phi \ldots \ldots \ldots \ldots
\end{array}
$$

Here, $\mathbf{J}_{0}$ and $\mathbf{J}_{\mathrm{e}}$ are the magnetizing current density and eddy current density, respectively. $\boldsymbol{v}, \Theta, \Lambda$ and $\phi$ are the reluctivity, electric conductivity, magnetic vector potential and electric scalar potential, respectively.

The cylindrical specimen is used as the test piece in this research (Fig. 1). The spiral geometry of the coil that surrounds the test piece may require a three-dimensional solution of the electromagnetic field, but we could assume that the internal heat generation induced by the electromagnetic field will exhibit rather uniform distributions in the circumferential direction, because a cylindrical specimen is used in the hot compression test. Then, the electromagnetic field is assumed to be axisymmetric which obeys Eq. (3). This assumption is also helpful in reducing the time required for

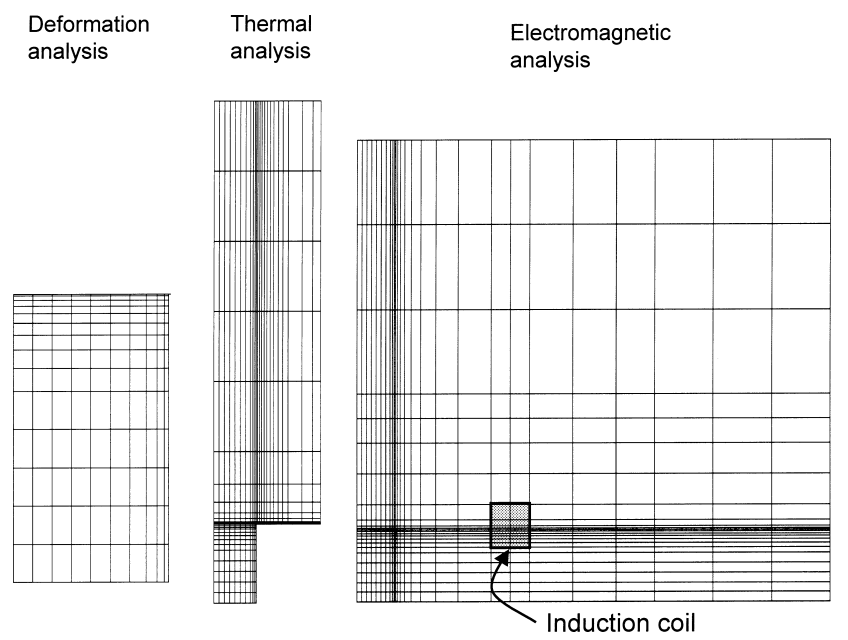

Fig. 2. FE mesh system used for electromagnetic, thermal and deformation analyses.

computing electromagnetic field.

$$
\begin{aligned}
& \frac{\partial}{\partial t}\left\{\frac{v_{z}}{r} \frac{\partial}{\partial r}\left(r \Lambda_{\theta}\right)\right\}+\frac{\partial}{\partial z}\left(v_{r} \frac{\partial \Lambda_{\theta}}{\partial z}\right) \\
& =-J_{0 \theta}+\Theta \frac{\partial \Lambda_{\theta}}{\partial t}+\Theta \frac{\partial \phi}{\partial \theta}
\end{aligned}
$$

Here, the subscripts denote directions in cylindrical coordinates. The last term $\partial \phi / \partial \theta$ in Eq. (3), which is related to $\operatorname{grad} \phi$ in Eq. (1), can be neglected because electric scalar potential will not distribute in the circumferential direction for axisymmetric problems. ${ }^{16)}$ The mesh system used for the electromagnetic analysis, deformation analysis and temperature analysis is illustrated in Fig. 2.

The vibration of the magnetic vector potential $\boldsymbol{\Lambda}$ is sinusoidal with respect to time $t$, so that Eq. (3) can be rewritten in the following forms using a complex number.

$$
\frac{\partial}{\partial r}\left\{\frac{v_{z}}{r} \frac{\partial}{\partial r}\left(r \dot{\Lambda}_{\theta}\right)\right\}+\frac{\partial}{\partial z}\left(v_{r} \frac{\partial \dot{\Lambda}_{\theta}}{\partial z}\right)=-\dot{J}_{0 \theta}+j \Theta \omega \dot{\Lambda}_{\theta}
$$




$$
\dot{J}_{0 \theta}=\dot{J}_{0 \theta} e^{j \omega t}
$$

$$
\begin{aligned}
\dot{\Lambda}_{\theta}=\dot{\Lambda}_{\mathrm{m}} e^{j(\omega t+\varphi)} & =\left(\Lambda_{\mathrm{m}} \cos \varphi+j \Lambda_{\mathrm{m}} \sin \varphi\right) e^{j \omega t} \\
& =\left(\Lambda_{\mathrm{R}}+j \Lambda_{\mathrm{I}}\right) e^{j \omega t} \ldots \ldots \ldots \ldots \ldots \ldots \ldots \ldots \ldots \ldots \ldots
\end{aligned}
$$

Here, " " " represents the expression using a complex number. $\omega$ and $\varphi$ are the angular velocity of the current source and the phase angle, respectively. Joule heat generation due to eddy current is expressed as Eq. (7). $\operatorname{Re}()$ indicates the real part of a complex number.

$$
\dot{q}_{\mathrm{e}}=\frac{1}{\Theta}\left(\operatorname{Re}\left(J_{\mathrm{e}}\right)\right)^{2}=\Theta \omega^{2} \Lambda_{\mathrm{m}}^{2}
$$

The internal heat generation $\dot{q}_{\mathrm{e}}$ obtained using Eq. (7) is transferred to the thermomechanical analysis of the test piece. The FE simulation code for the electromagnetic analysis is developed by referring to Eqs. (1)-(7), taking the magnetic vector potential of nodal points as a representative parameter.

\subsection{Thermal Analysis}

The Arbitrary Lagrangean Eularian (ALE) scheme is used in the thermal analysis of the tool, ${ }^{14)}$ because the coordinate of nodal points embedded in the tool moves towards the radial direction due to the plastic flow of the test piece during a hot compression test. Then, the following equation is applied to thermal analysis.

$$
\rho c\left(\frac{\partial T}{\partial t}-v_{r} \frac{\partial T}{\partial r}\right)=\frac{\kappa}{r}\left(r \frac{\partial^{2} T}{\partial r^{2}}+r \frac{\partial^{2} T}{\partial z}\right)+\dot{Q}
$$

Here, $\rho, c$ and $\kappa$ are the density, specific heat and thermal conductivity, respectively. $v_{r}$ is the radial velocity of the test piece at the interface between the tool and the test piece, and $v_{r}$ is zero during preheating. It is assumed that all the energy dissipations due to plastic deformation are transferred to heat generation, such as $\dot{Q}=\bar{\sigma} \dot{\bar{\varepsilon}}$ Also, the internal heat generation induced by the Joule heat $\dot{q}_{\mathrm{e}}$ should be added to this term. Then, the total amount of internal heat generation in the thermal analysis is expressed as

$$
\dot{Q}=\bar{\sigma} \dot{\bar{\varepsilon}}+\Theta \omega^{2} \Lambda_{\mathrm{m}}^{2}
$$

The first term on the right-hand-side of Eq. (9) is zero during the thermo-mechanical analysis of preheating.

\section{Inverse Analysis of Hot Compression for Obtaining Flow Curve}

\subsection{Experimental Condition}

Table 1 shows the chemical composition of the test piece used for the hot compression test. Plain carbon steel without micro-alloying elements is chosen as an example. Experimental conditions are summarized in Table 2. The testing temperatures chosen are $1173 \mathrm{~K}, 1273 \mathrm{~K}$ and $1373 \mathrm{~K}$, which cover industrial hot-forming temperatures. The temperature of the test piece is measured at midheight of the test piece, and is controlled to maintain the testing temperature as a target, by changing the electric current of induction heating. Axial true strain rate is controlled during the hot compression test, and their target values are selected as $1 / \mathrm{s}, 10 / \mathrm{s}$ and $50 / \mathrm{s}$. It should be noted that the above-men-
Table 1. Chemical composition of test piece.

\begin{tabular}{|c|c|c|c|c|c|c|c|}
\hline & $\mathrm{C}$ & $\mathrm{Si}$ & $\mathrm{Mn}$ & $\mathrm{P}$ & $\mathrm{S}$ & $\mathrm{Cu}$ & $\mathrm{Cr}$ \\
\hline$\%$ & 0.19 & 0.2 & 0.4 & 0.019 & 0.011 & 0.16 & 0.11 \\
\hline
\end{tabular}

Table 2. Experimental conditions.

\begin{tabular}{|c|c|c|c|c|}
\hline Layer & Test piece & Tool $^{18)}$ & Mica ${ }^{18)}$ & Scale \\
\hline Material & $\mathrm{S} 20 \mathrm{C}$ & $\mathrm{Si}_{3} \mathrm{~N}_{4}$ & Mica & $\mathrm{FeO}$ \\
\hline $\begin{array}{l}\text { Density, } \\
\rho / \mathrm{kg} \mathrm{m}^{-3}\end{array}$ & 7800 & 3200 & 2100 & 4300 \\
\hline $\begin{array}{l}\text { Specific heat } \\
\text { capacity, } \\
c / \mathrm{J} \mathrm{kg}^{-1} \mathrm{~K}^{-1}\end{array}$ & $\begin{array}{c}500-1600^{17}{ }^{1} \\
\text { (See fig.3) }\end{array}$ & 710 & 880 & 790 \\
\hline $\begin{array}{l}\text { Thermal } \\
\text { Conductivity, } \\
\kappa / \mathrm{W} \mathrm{m}^{-1} \mathrm{~K}^{-1}\end{array}$ & 23.6 & 29.3 & 1.22 & $\begin{array}{c}0.06 \\
\text { (before hot compression test) } \\
1.5 \\
\text { (during hot compression test) }\end{array}$ \\
\hline $\begin{array}{c}\text { Heat transfer } \\
\text { coefficient, } \\
\mathrm{H} / \mathrm{W} \mathrm{m}^{-2} \mathrm{~K}^{-1}\end{array}$ & 11.6 & 11.6 & 11.6 & 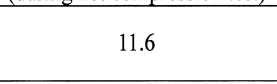 \\
\hline $\begin{array}{c}\text { Thickness, } \\
/ \mu \mathrm{m}\end{array}$ & - & - & 200 & 30 \\
\hline $\begin{array}{c}\text { Radiation coefficient, } \\
E\end{array}$ & \multicolumn{4}{|c|}{0.78} \\
\hline $\begin{array}{c}\text { Shape factor, } \\
\varphi\end{array}$ & \multicolumn{4}{|c|}{1} \\
\hline
\end{tabular}

\begin{tabular}{|c|c|}
\hline $\begin{array}{c}\text { Testing temperature } \\
/ \mathrm{K}\end{array}$ & $1173,1273,1373$ \\
\hline Strain rate $\dot{\bar{\varepsilon}} / \mathrm{s}^{-1}$ & $1,10,50$ \\
\hline Material of tool & $\mathrm{Si}_{3} \mathrm{~N}_{4}$ \\
\hline Atmosphere & Vacuum $(0.1 \mathrm{~Pa})$ \\
\hline Lubricant & Mica sheet \\
\hline
\end{tabular}

Table 3. Constants used in electromagnetic analysis of test piece.

\begin{tabular}{|c|c|c|}
\hline Layer & $\begin{array}{c}\text { Magnetic permeability } \\
\text { rate }{ }^{99} 1 / \nu\end{array}$ & $\begin{array}{c}\text { Electric conductivity / } \\
\Theta \times 10^{7}[\mathrm{~S} / \mathrm{m}]^{18)}\end{array}$ \\
\hline Test piece & $1-100$ (See Fig.3) & $0.055-1.03($ see Fig.3) \\
\hline Coil & 0.99998 & 5.8 \\
\hline Atmosphere & 1. & 0. \\
\hline
\end{tabular}

Table 4. Constants used in thermal analysis of test piece.

tioned testing temperatures and strain rates are the target values for operating the hot compression testing machine. Strain rate and temperature distribute across the cross section of the test piece, because of the inhomogeneous distributions in plastic deformation and temperature. Variations, or errors, in flow stress resulting from these distributions are compensated in the inverse analysis of the flow curve, ${ }^{14)}$ which enables us to obtain a flow curve with ideal uniaxial deformation at a constant temperature.

\subsection{Thermomechanical and Electromagnetic Con- stants}

The thermal and electromagnetic constants used in the analysis of induction heating are shown in Tables $\mathbf{3}$ and $\mathbf{4}$. The specific heat $c$, magnetic permeability rate and electric conductivity $\Theta$ are dependent on temperature, as is shown in Fig. 3. The peak specific heat corresponds to the Curie temperature. The transient change in specific heat due to the latent heat during the phase transformation from a bcc lattice to an fcc lattice is neglected because it has little effect on the temperature distribution in the cross section of the test piece. The specific heat shown in Fig. 3 is that of pure iron. The shift in transformation temperature from that of pure iron to that of $0.2 \mathrm{C}-\mathrm{Mn}$ steel is compensated in the present investigation. The coil is $22 \mathrm{~mm}$ in diameter and turns twice around the test piece. The frequency of induction heating is $100 \mathrm{kHz}$.

Figure 4 shows the heat treatment curve of the hot com- 
pression test. The test piece temperature is elevated up to $1473 \mathrm{~K}$ at a rate of $10 \mathrm{~K} / \mathrm{s}$, and normalized for $120 \mathrm{~s}$. Then, it is cooled to the testing temperature at a rate of $2 \mathrm{~K} / \mathrm{s}$ and held at such temperature for $10 \mathrm{~s}$ to ensure a rather uniform temperature distribution of the test piece. Finally, upsetting is conducted at the test temperature. Induction heating is still activated during upsetting to control the temperature of the test piece. The temperature of the test piece, which is represented by that at midheight of the test piece shown in Fig. 1, is controlled to maintain the above-mentioned temperature history by changing the electric current of induction heating. This requires the overall temperature analysis

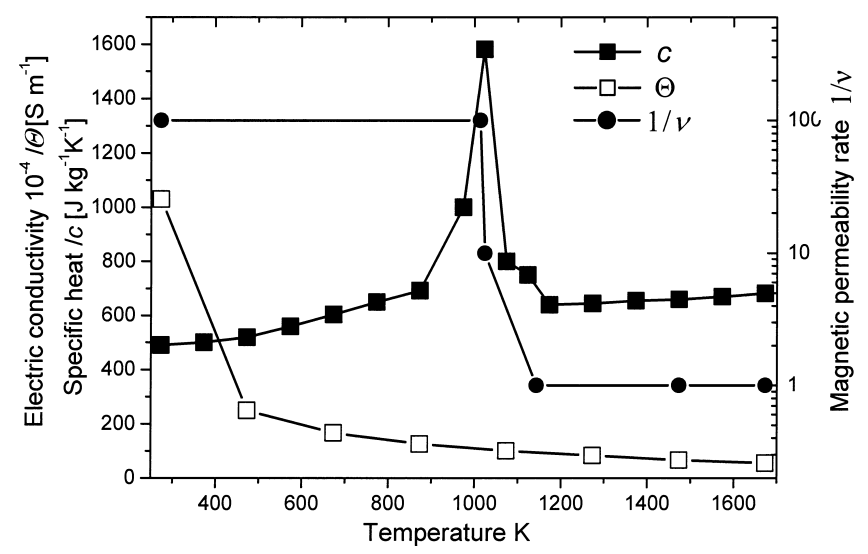

Fig. 3. Variations in specific heat, magnetic permeability rate and electric conductivity versus temperature.

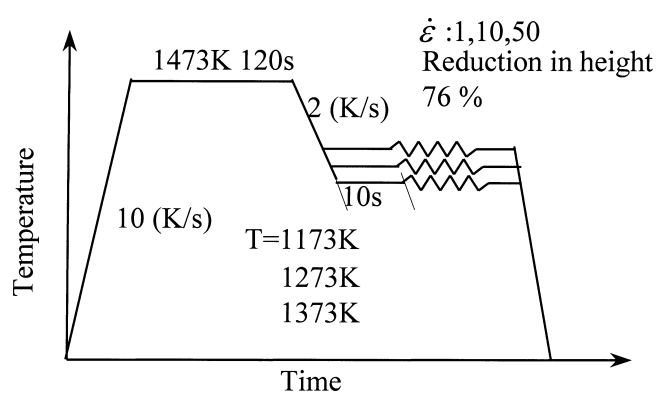

Fig. 4. Heat treatment curve of hot compression test. and electromagnetic analysis of induction heating from the beginning to the end of the hot compression test, aiming to acquire the precise distribution of temperature required in the inverse analysis to obtain an accurate flow curve. The comparison of the measured temperature with the estimated temperature is shown in Fig. 5. It is clear that the temperature distributions of the test piece and tool after the normalization as well as before the upsetting are precisely analyzed by the electromagnetic analysis and thermal analysis of the test piece presented in the previous section, using the constants shown in Tables 3 and 4, and Fig. 3. The friction coefficient between tools and test piece used in the thermomechanical analysis is $\mu=0.2$. This value is determined by comparing the bulge profile of deformed test piece obtained by the thermomechanical FE analysis and experiment, and is the same value as that used in the previous investigation. ${ }^{14)}$

Figure 6 shows another example for evaluating the accuracy of the electromagnetic and thermomechanical analyses. Here, the transient change in the temperature of the surface of test piece during the upsetting is shown for several axial positions. It is clear that the transient change in the temperature distribution is in good agreement with the results of the electromagnetic and thermomechanical analyses. We use the temperature at the midheight of surface as the controlling variable in experiment as well as in the thermomechanical analysis. The temperature at the center of the test piece would be the better controlling variable, however, the drilled hole to install the thermocouple will be the source of temperature elevation due to the surface effect of drilled hole during induction heating, and the measured inside temperature will not be identical with the temperature at the center of test piece without the hole. In addition, fully three-dimensional electromagnetic and thermomechanical FE analyses, which require much longer time for computation, will be needed to reproduce the temperature of test piece with the hole, if we aim to control the temperature inside the test piece.

During the hot compression test, the electric current of induction heating is controlled to maintain the temperature

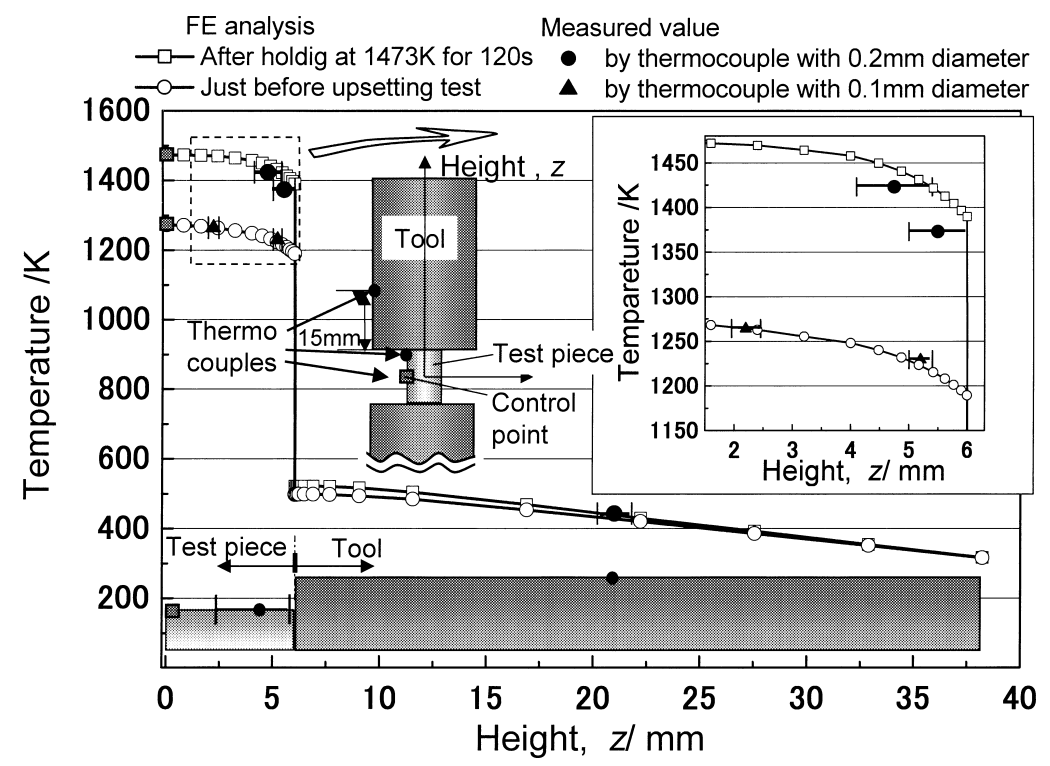

Fig. 5. Comparison of measured temperature and temperature estimated by FE analysis. 


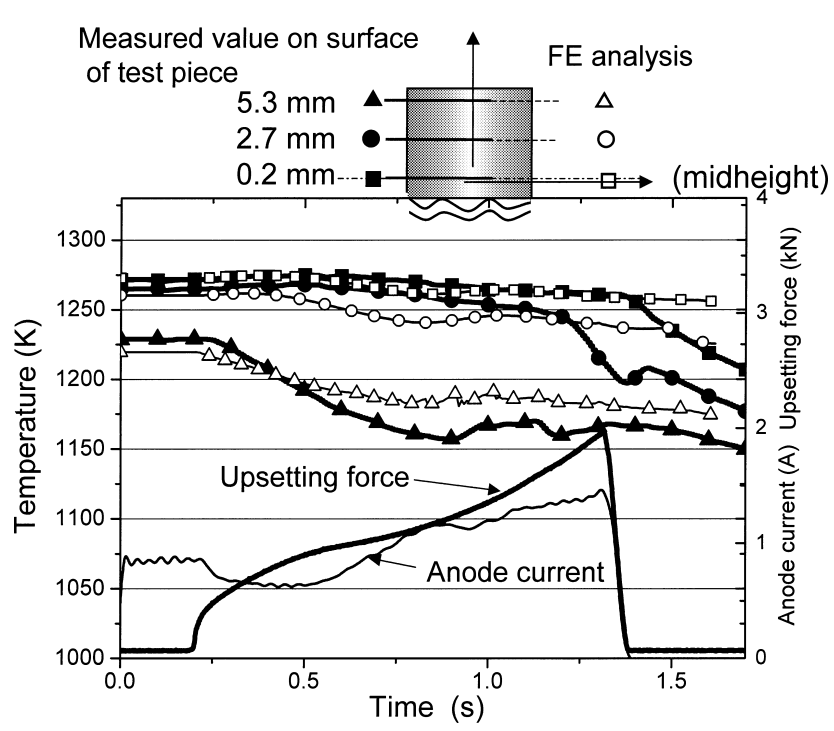

Fig. 6. Transient change in surface temperature distribution during upsetting.

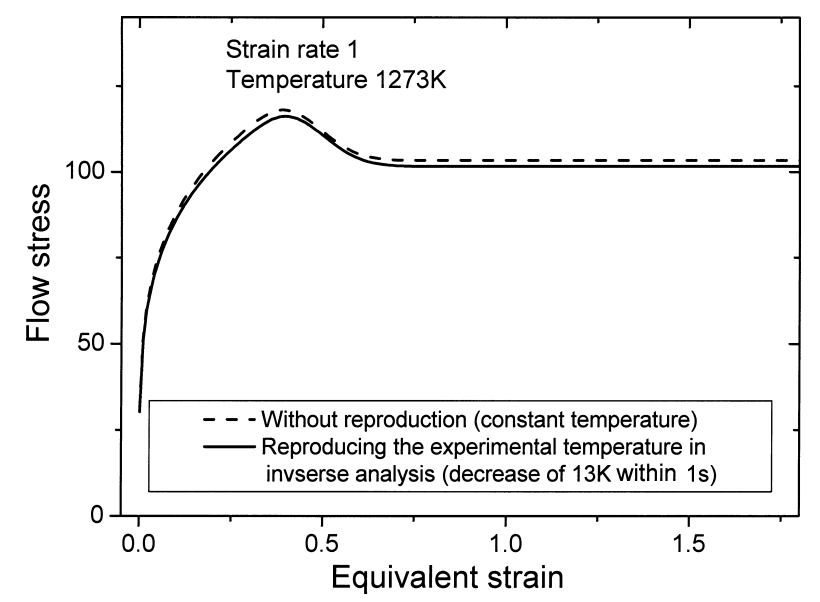

Fig. 7. Variation in flow curve with and without reproduction of measured temperature at midheight of test piece during upsetting.

at midheight of the surface of the test piece as the target value. But due to the delay in the controlling system or other inevitable error in experiment, the temperature at midheight of the test piece decreased to approximately $13 \mathrm{~K}$ in $1 \mathrm{~s}$. This transient change in temperature can be reproduced in the electromagnetic and thermal analyses, as is shown in Fig. 6. When the strain rate is high, temperature at midheight of the test piece increases due to the internal heat generation, and it may exceed the target value. Electric current of induction coil is automatically turned off by PID controller during compression test, and this situation is reproduced in the thermomechanical and electromagnetic analyses to minimize the deviation of analytical temperature from the experimental one.

Figure 7 shows the variation in the flow curve with and without the reproduction of measured temperature at midheight of the test piece during the upsetting. A transient change in temperature is reproduced in this analysis upon changing the electric current of induction heating in the electromagnetic analysis. It is clear that the reproduction of the experimental temperature is necessary in inverse analysis in order to determine an accurate flow curve. This means that the electromagnetic analysis of induction heating during preheating as well as upsetting is indispensable to obtaining an accurate flow curve.

\section{Regression of Parameters in Flow Curve to Obtain Generalized Form of Flow Curve}

\subsection{Inverse Analysis of Hot Compression for Obtain- ing Coefficients in Flow Curve}

The flow curve of a metal under dynamic recrystallization is represented by Eq. (10), which we proposed previously. $^{14)}$

$$
\begin{array}{ll}
\bar{\sigma}=F_{1} \bar{\varepsilon}^{n} & \left(\bar{\varepsilon} \leq \varepsilon_{\mathrm{c}}\right) \\
\bar{\sigma}=F_{1} \exp \left[a\left(\bar{\varepsilon}+\varepsilon_{\max }\right)^{2}\right]+F_{3} & \left(\bar{\varepsilon} \geq \varepsilon_{\mathrm{c}}\right)
\end{array}
$$

Here, $\varepsilon_{\mathrm{c}}$ denotes the critical strain for the onset of dynamic recrystallization. When the equivalent strain is smaller than $\varepsilon_{\mathrm{c}}$, work hardening and dynamic recovery occur. A simple power law is used to describe the flow curve of a smaller strain. $\varepsilon_{\max }$ is the strain when flow stress reaches its maximum value, and $F_{3}$ corresponds to the steady-state stress $\sigma_{\mathrm{s}}$ when the deforming metal is in perfect dynamic recrystallization. $a, F_{2}$ and $\varepsilon_{\max }$ are dependent parameters that are calculated from the continuity of the flow curve in the zeroorder, first-order and second-order derivatives at $\bar{\varepsilon}=\varepsilon_{\mathrm{c}}$. Then, $\varepsilon_{\mathrm{c}}, F_{1}, n$, and $F_{3}$ are four independent parameters for the standard description of the flow curve expressed by Eq. (10).

The generalized form of the flow curve expressed by Eq (10) can be written as

$$
\bar{\sigma}^{*}=\bar{\sigma} \cdot \dot{\bar{\varepsilon}}^{m} \frac{\exp (A / T)}{\exp \left(A / T_{0}\right)}
$$

where $T_{0}$ is the reference temperature, that is, the target testing temperature. The rate sensitivity $m$ and the temperature sensitivity $A$ are additional independent parameters in the generalized form of the flow curve.

The flow chart of the inverse analysis is shown in Fig. 8. The internal loop is used in determining $\varepsilon_{c}, F_{1}, n$ and $F_{3}$ under the testing conditions at a certain testing temperature and strain rate. The external loop is the regression analysis, which is explained in the next section, for determining $m$ and $A$ using the coefficients in the flow curve for several strain rates and testing temperatures.

Table 5 summarizes the coefficients in the flow curve obtained by the inverse analysis, using the initial guess of rate sensitivity $m_{0}=0.13$ and temperature sensitivity $A_{0}=$ $3400 .^{7,14)}$

\subsection{Regression of Rate Sensitivity and Temperature Sensitivity}

Equation (11) is transformed into Eq. (12).

$$
\bar{\sigma}^{*}=\bar{\sigma}^{\text {sep }} \cdot \dot{\bar{\varepsilon}}^{m} \exp (A / T) \text {.. }
$$

Here, $\bar{\sigma}^{\text {sep }}=\bar{\sigma} / \exp \left(A / T_{0}\right)$. If $T$ equals the reference temperature $T_{0}$ and the plastic strain is less than the critical strain $\varepsilon_{\mathrm{c}}$, the flow stress is expressed by Eq. (13), which is derived by substituting Eq. (10) into Eq. (12). 


$$
\bar{\sigma}^{*}=\bar{\sigma} \cdot \dot{\bar{\varepsilon}}^{m}=F_{1} \bar{\varepsilon}^{n} \dot{\bar{\varepsilon}}^{m} \quad\left(\varepsilon<\varepsilon_{\mathrm{c}}\right)
$$

As can be seen in Table 5, work hardening coefficients $n$ are scattered, and the clear tendency of $n$ to vary with temperature and strain rate is not observed. The physical consideration in determining the work hardening coefficient $n$ is that it may not be strongly dependent on temperature and strain rate. $^{7,9,20)}$ We have known $n$ to be approximately 0.2 in many articles on hot rolling. ${ }^{20)}$ Also, $n$ may include an error because it is determined by the flow curve at a small strain, which is affected by an unstable transient situation at the start of upsetting. Then, the arithmetic average of the work hardening coefficient $\bar{n}$ is used instead of the scattered $n$ values. Accordingly, the plastic modulus $F_{1}$ is modified to $F_{1}^{\prime}$ using

$$
\int_{0}^{\varepsilon_{\mathrm{c}}} F_{1}^{\prime} \bar{\varepsilon}^{\bar{n}} d \bar{\varepsilon}=\int_{0}^{\varepsilon_{\mathrm{c}}} F_{1} \bar{\varepsilon}^{n} d \bar{\varepsilon}
$$

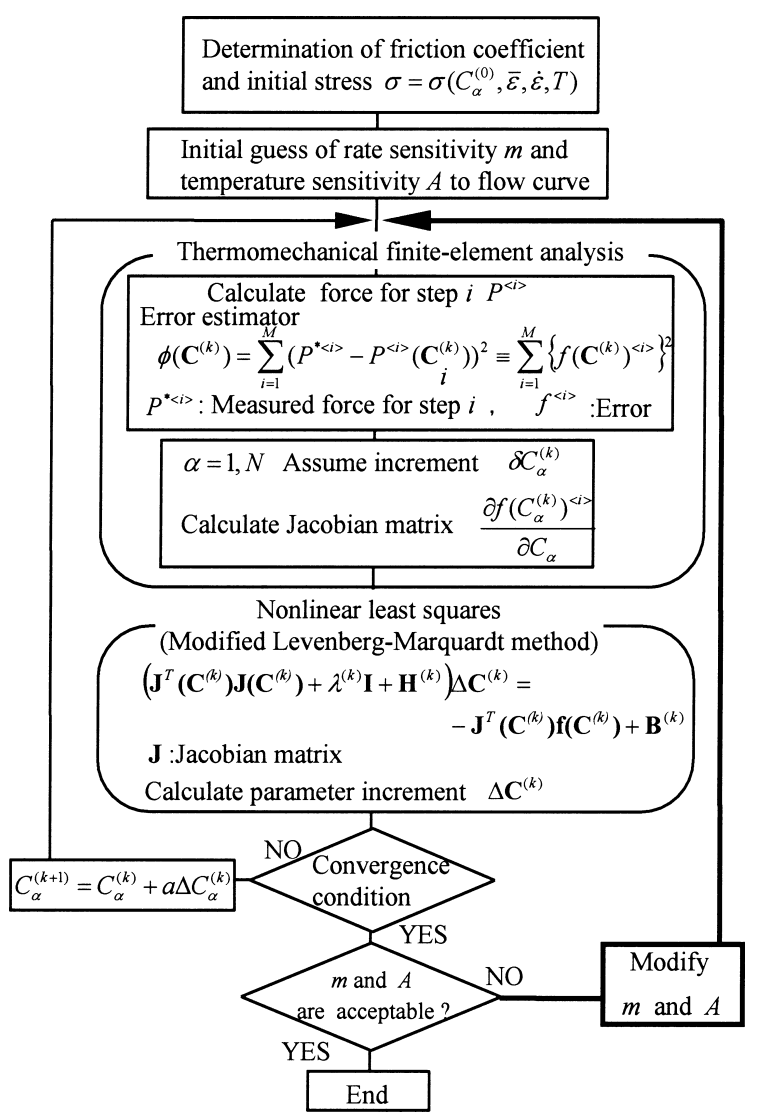

Fig. 8. Flowchart of inverse analysis.
Plastic modulus could be regarded as independent of strain rate. Then, the rate sensitivity $m$ could be determined as a function of test temperature using Eq. (15). $m_{0}$ is the initial guess of rate sensitivity used to obtain the current $\varepsilon_{\mathrm{c}}, F_{1}, n$ and $F_{3}$.

$$
\frac{\bar{\sigma}^{*}}{\bar{\varepsilon}^{\bar{n}}}=F_{1}^{\prime} \dot{\bar{\varepsilon}}^{m_{0}}=F_{1}^{\mathrm{opt}} \dot{\bar{\varepsilon}}^{m}
$$

$F_{1}^{\text {opt }}$ is the optimized plastic modulus, which is dependent on test temperature. The following equation could be used to regress the rate sensitivity $m$. The rate sensitivity $m$ is calculated for each test temperature.

$$
\log \left(F_{1}^{\prime} \dot{\bar{\varepsilon}}^{m_{0}}\right)=\log \left(F_{1}^{\text {opt }} \dot{\bar{\varepsilon}}^{m}\right)=m \log (\dot{\bar{\varepsilon}})+\log \left(F_{1}^{\text {opt }}\right)
$$

From the logarithmic plot of $\log \left(F_{1}^{\prime} \dot{\bar{\varepsilon}}^{m_{0}}\right)$ versus $\log (\dot{\bar{\varepsilon}})$, the rate sensitivity $m$ is determined from the slope and $F_{1}^{\text {opt }}$ from the intercept.

As described previously, the optimized plastic modulus $F_{1}^{\text {opt }}$ is dependent on temperature. Hence, from the obtained $F_{1}^{\text {opt }}$ at a certain temperature $T^{*}, F_{1}^{\text {opt }}$ can be transformed into Eq. (17) to compensate for the variation in test temperature.

$$
F_{1}^{\mathrm{opt}}=\left.F_{1}^{\mathrm{opt}}\right|_{T=T^{*}} \cdot \exp \left\{A\left(\frac{1}{T}-\frac{1}{T^{*}}\right)\right\}
$$

Substituting Eq. (17) into Eq. (15), we obtain

$$
\begin{aligned}
\frac{\bar{\sigma}^{*}}{\bar{\varepsilon}^{\bar{n}} \dot{\bar{\varepsilon}}^{m}} & =F_{1}^{\prime} \dot{\bar{\varepsilon}}^{\left(m_{0}-m\right)}=F_{1}^{\mathrm{opt}} \\
& =\left.F_{1}^{\mathrm{opt}}\right|_{T=T^{*}} \cdot \exp \left\{A\left(\frac{1}{T}-\frac{1}{T^{*}}\right)\right\}
\end{aligned}
$$

Then, Eq. (19) is used for the regression analysis to determine the temperature sensitivity $A$.

$$
\ln \left(F_{1}^{\prime} \dot{\overline{\mathcal{E}}}^{\left(m_{0}-m\right)}\right)=\ln \left(\left.F_{1}^{\mathrm{opt}}\right|_{T=T^{*}}\right)+A\left(\frac{1}{T}-\frac{1}{T^{*}}\right) \ldots
$$

The schematics of the regression of the rate sensitivity $m$ and temperature sensitivity $A$ are summarized in Fig. 9. Figure 10 shows the different rate sensitivities $m$. It is clear that rate sensitivities $m$ is dependent on temperature. After a few iterations, the rate sensitivity $m$ becomes constant.

Table 5. Coefficients in flow curve obtained by inverse analysis, using the initial guess of rate sensitivity $m_{0}=0.13$ and temperature sensitivity.

\begin{tabular}{|c|c|c|c|c|c|c|c|}
\hline $\begin{array}{c}\text { Strain } \\
\text { rate, } \dot{\bar{\varepsilon}}\end{array}$ & $\begin{array}{c}\text { Temperature, } \\
T / \mathrm{K}\end{array}$ & $F_{1}$ & $n$ & $\varepsilon_{c}$ & $\varepsilon_{\max }$ & $F_{3}$ & Error* \\
\hline 1 & 1373 & 125.27 & 0.260 & 0.182 & $(0.238)$ & 72.00 & $0.63 \%$ \\
\hline 10 & 1373 & 106.24 & 0.185 & 0.320 & $(0.477)$ & 72.64 & $1.50 \%$ \\
\hline 50 & 1373 & 105.57 & 0.200 & 0.475 & $(0.671)$ & 79.34 & $0.74 \%$ \\
\hline 1 & 1273 & 155.43 & 0.248 & 0.288 & $(0.349)$ & 106.43 & $0.63 \%$ \\
\hline 10 & 1273 & 131.06 & 0.213 & 0.451 & $(0.634)$ & 96.00 & $0.99 \%$ \\
\hline 50 & 1273 & 131.17 & 0.220 & 0.536 & $(0.894)$ & 79.16 & $1.20 \%$ \\
\hline 1 & 1173 & 190.31 & 0.205 & 0.445 & $(0.555)$ & 150.32 & $1.41 \%$ \\
\hline 10 & 1173 & 176.64 & 0.213 & 0.549 & $(0.899)$ & 111.71 & $1.18 \%$ \\
\hline 50 & 1173 & 163.01 & 0.232 & 0.516 & $(1.008)$ & 23.77 & $1.90 \%$ \\
\hline
\end{tabular}

Average error in upsetting force between analysis and experiment.

Temperature sensitivity $A_{0}=3400 ;$ rate sensitivity $m_{0}=0.13$ 
During the iteration, temperature sensitivity is also optimized using the following method. Figure 11 shows the plot of parameters calculated using Eq. (16). After a few iterations, the slope $A=4260$ is obtained. This temperature sensitivity is larger than that obtained by Misaka, ${ }^{7)}$ that is, $A=3400$. The above-mentioned temperature sensitivity $A$ is determined from the plastic modulus, which reflects work hardening and dynamic recovery. Another approach is to use the steady-state stress $\sigma_{\mathrm{s}}\left(=F_{3}\right)$, which is also a function of test temperature. $\sigma_{\mathrm{s}}$ is precisely obtained only when the test piece is in perfect dynamic recrystallization. As these
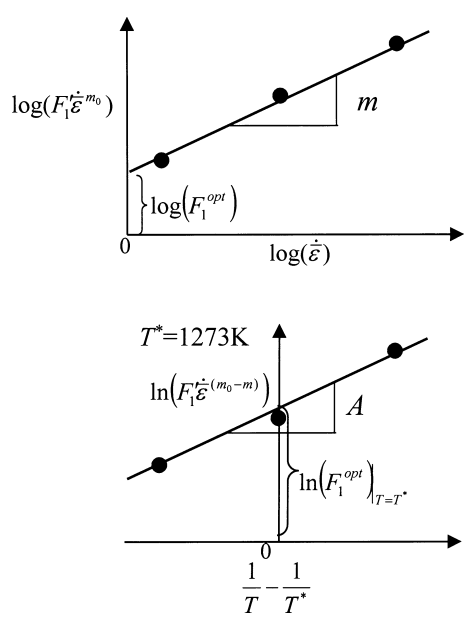

Fig. 9. Schematics of regression of rate sensitivity and temperature sensitivity.

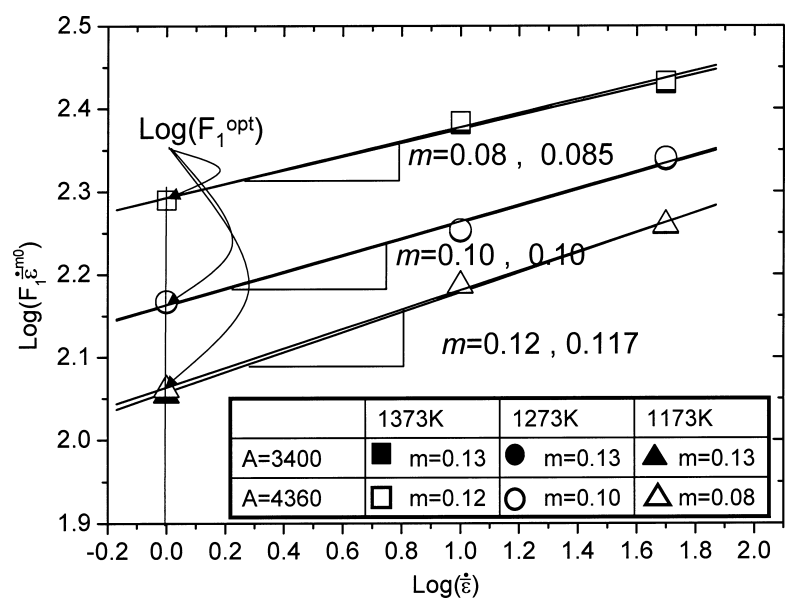

Fig. 10. Regression of temperature sensitivity $m$.

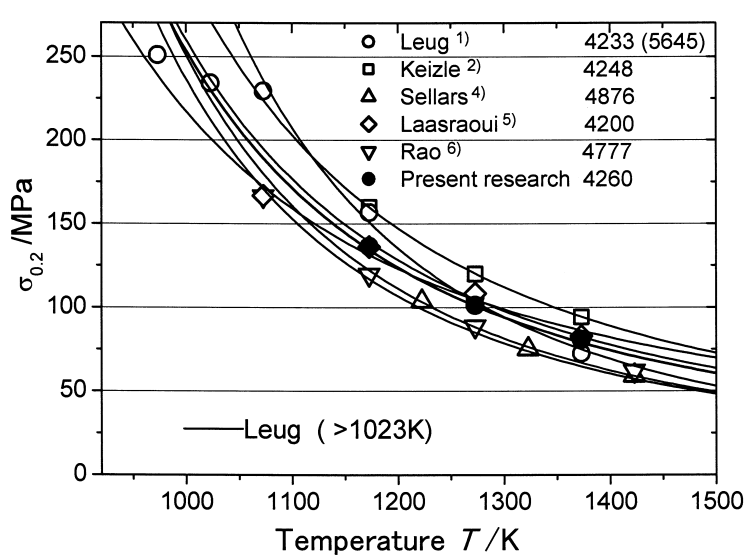

values obtained under the testing conditions of a low temperature and a high strain rate are not suitable for calculating the steady-state stress $\sigma_{\mathrm{s}}\left(=F_{3}\right)$, it is not appropriate for computing temperature sensitivity accurately. For this reason, $T=1173 \mathrm{~K} / \dot{\bar{\varepsilon}}=50, \quad T=1173 \mathrm{~K} / \dot{\bar{\varepsilon}}=10$ and $T=$ $1273 \mathrm{~K} / \dot{\bar{\varepsilon}}=50$ are neglected in the regression of $F_{3}$ versus the test temperature $T$, as is shown in Fig. 12. The temperature sensitivity obtained from the steady-state stress is $A^{\prime}=4650$, which is only $9 \%$ larger than that obtained from the plastic modulus $F_{1}$. This may confirm the accuracy of the temperature sensitivity $A=4260$ obtained in this research. The rate sensitivity $m$ and temperature sensitivity $A$ obtained in this research are compared with other measure-

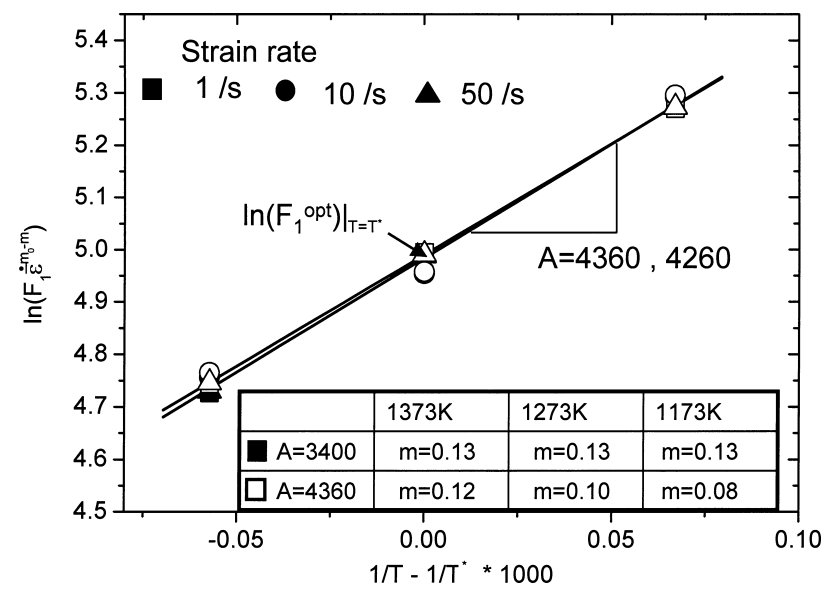

Fig. 11. Regression of temperature sensitivity $A$.

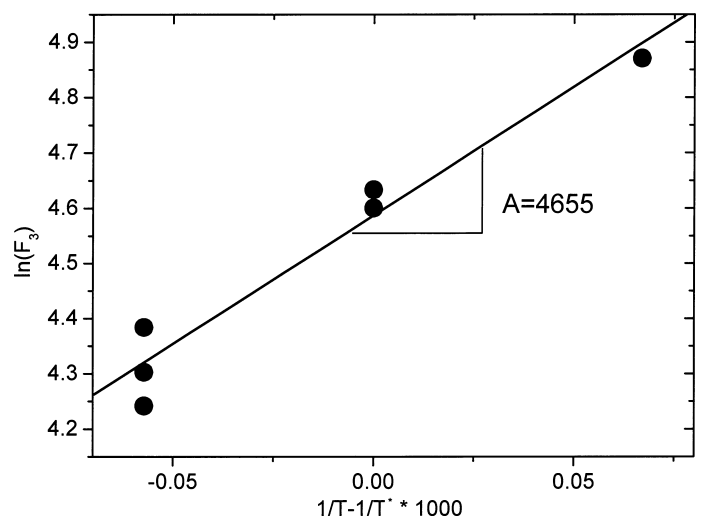

Fig. 12. Regression of temperature sensitivity using steady-state stress $\sigma_{\mathrm{s}}\left(=F_{3}\right)$.

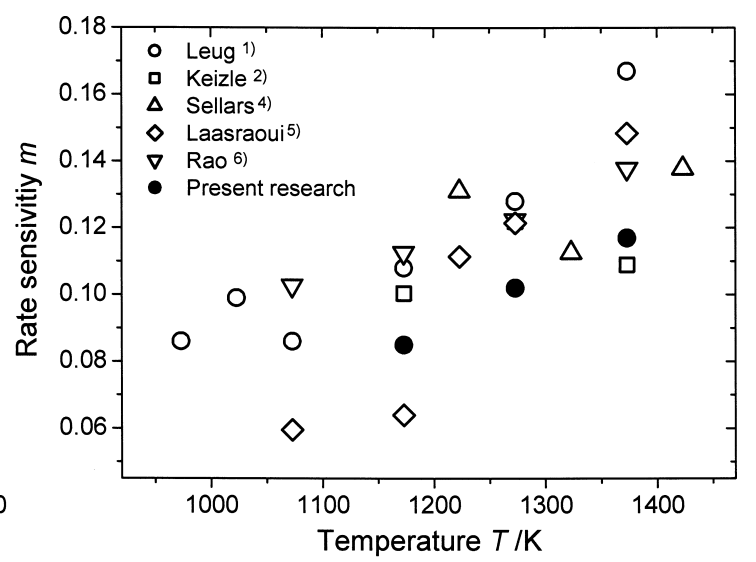

Fig. 13. Comparison of measured rate sensitivity and temperature sensitivity with those of other research studies. 
ments ${ }^{1,2,4-6)}$ in Fig. 13. It is worth noting that the previously obtained data of the temperature sensitivity $A$ are regressed using $20 \%$ proof stress $\sigma_{0.2}$ at different plastic strains, which includes the error in estimating the temperature sensitivity as the data are values at different plastic strains. Plastic coefficient $F_{1}$ does not include such type of error.

\subsection{Generalized Form of Flow Curve for $\mathbf{0 . 2 0 C}-\mathrm{Si}$ - Mn Steel}

The rate sensitivity $m$ can be expressed as a linear function as Eq. (20) because $\mathrm{m}$ is dependent on temperature, as is shown in Fig. 10.

$$
m=B_{4}+B_{5} T
$$

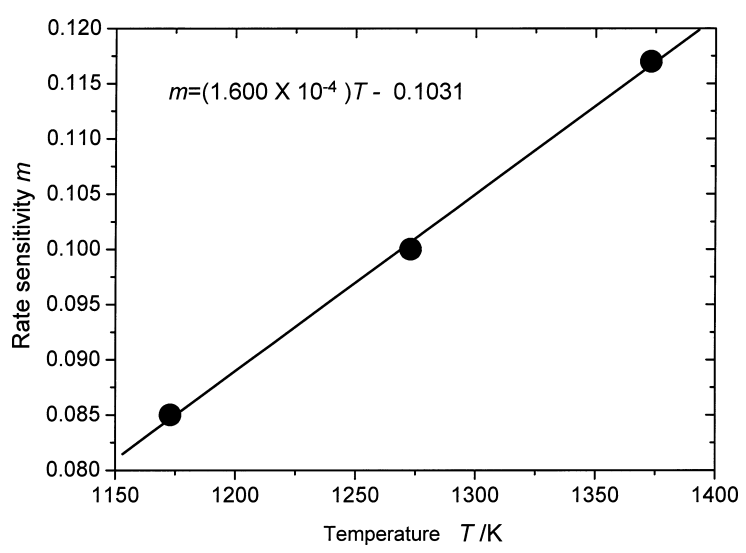

Fig. 14. Formulation of rate sensitivity as function of temperature

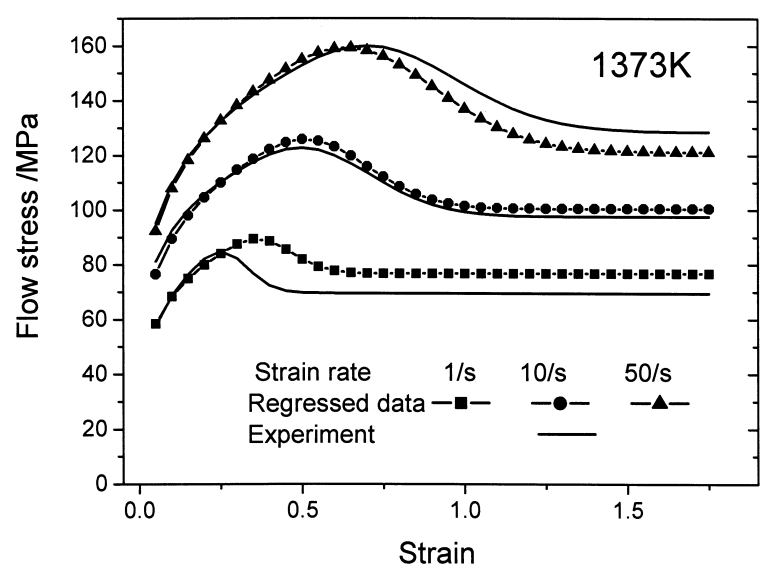

The critical strain for the onset of dynamic recrystallization $\varepsilon_{\mathrm{c}}$ is assumed as a function of the Zener-Hollomon parameter as expressed as

$$
\begin{gathered}
\varepsilon_{\mathrm{c}}=B_{1} Z^{B_{2}} \ldots \ldots \\
Z=\dot{\bar{\varepsilon}} \exp \left(\frac{B_{3}}{T}\right) .
\end{gathered}
$$

The expressions of $m$ and $\varepsilon_{\mathrm{c}}$ are shown in Figs. 14 and 15. A general description of the flow curve for $0.20 \mathrm{C}-\mathrm{Si}-\mathrm{Mn}$ steel is expressed as

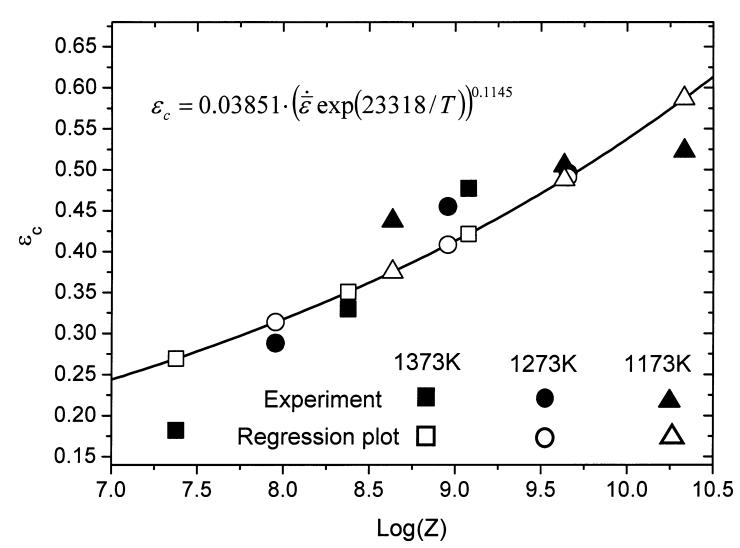

Fig. 15. Formulation of $\varepsilon_{\mathrm{c}}$ as function of Zener-Hollomon parameter.

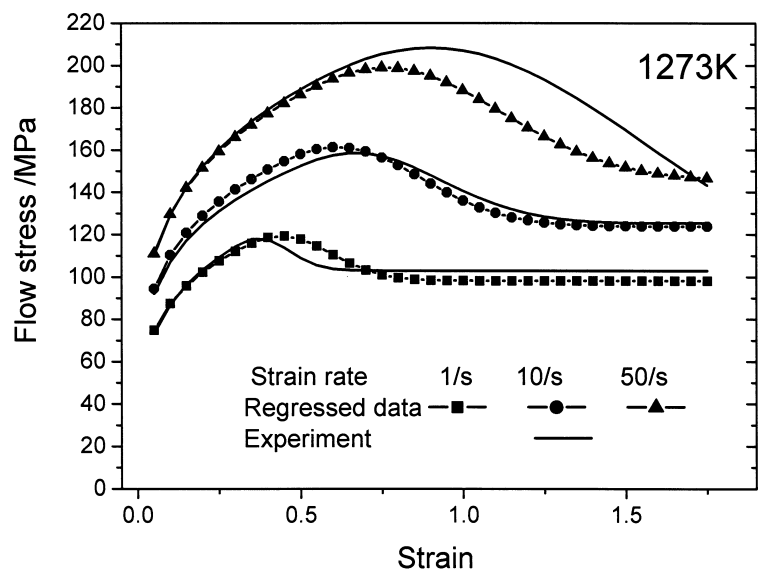

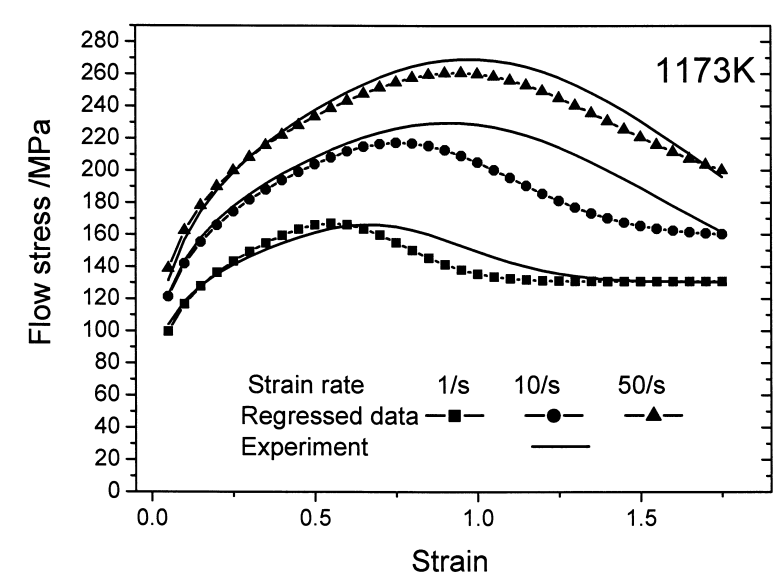

Fig. 16. Accuracy of generalized flow curve for $0.20 \mathrm{C}-\mathrm{Si}-\mathrm{Mn}$ steel. 


$$
\begin{aligned}
& \bar{\sigma}^{*}=147 \bar{\varepsilon}^{0.225} \dot{\bar{\varepsilon}}^{(-0.1031+0.00016 T)} \exp \left\{4260\left(\frac{1}{T}-\frac{1}{1273}\right)\right\} \\
& \left(\bar{\varepsilon} \leq \varepsilon_{\mathrm{c}}\right) \\
& \begin{aligned}
\bar{\sigma}^{*}= & \left\{F_{2} \exp \left[a\left(\bar{\varepsilon}-\varepsilon_{\max }\right)^{2}\right]+91.78\right\} \dot{\bar{\varepsilon}}^{(-0.1031+0.00016 T)} \\
& \times \exp \left\{4260\left(\frac{1}{T}-\frac{1}{1273}\right)\right\} \quad\left(\bar{\varepsilon}>\varepsilon_{\mathrm{c}}\right)
\end{aligned}
\end{aligned}
$$

$$
\varepsilon_{\mathrm{c}}=0.03851\left\{\dot{\bar{\varepsilon}} \exp \left(\frac{23318}{T}\right)\right\}^{0.1145}
$$

The accuracy of the generalized flow curve shown in Eq. (23) is shown in Fig. 16. It is clear that this form can describe the flow curve for wide ranges of hot-forming temperature and strain rate with acceptable accuracy. Equation (23) is effective in the temperature range from 1173 to $1373 \mathrm{~K}$, however, it may include a certain amount of error at around $1173 \mathrm{~K}$, because there exists the chilled zone in the test piece near the contact area with tools, where the extrapolated value of flow stress is adopted in the thermomechanlcal FE analysis.

\section{Conclusion}

The electromagnetic analysis of induction heating during heating and hot compression is introduced in thermomechanical FEM in inverse analysis, aiming to realize a more accurate estimation of the inhomogeneous temperature field of the test piece. From the accurately determined coefficients of the flow curve corresponding to the wide ranges of temperature and strain rate, a generalized description of the flow curve is successfully obtained. Finally, a generalized flow curve for $0.20 \% \mathrm{C}-\mathrm{Si}-\mathrm{Mn}$ steel is regressed successfully, which covers the strain rate range from $1 / \mathrm{s}$ to $50 / \mathrm{s}$ and the temperature range from 1173 to $1373 \mathrm{~K}$. The generalized flow curve obtained can predict flow stress with ac- ceptable accuracy. It is worth noting that the proposed method can be applied to other types of steel with different alloying elements and nonferrous metals, for which a practical equation, which can be used to calculate the flow curve implemented in FE analysis, is not yet available at present.

\section{REFERENCES}

1) V. W. Leug and H. G. Muller: Arch. Eisenhüttenwes., 28 (1957), 505.

2) O. Kienzle: Z. Metallkd., 55 (1964), 688.

3) H. Suzuki, S. Hashizume, Y. Yabuki, Y. Ichihara, S. Nakajima and K. Kenmochi: Report of IIS The University of Tokyo, 18-3 (1968), 140.

4) C. M. Sellers: Hot Working and Forming Process, ed. by C. M. Sellers and G. J. Davies, The Metal Society, London, (1980), 3.

5) A. Laasraoui and J. J. Jonas: Metall. Trans. A, A22 (1991), 1545.

6) K. P. Rao, E. E. B. Hawbolt, H. J. McQeen and D. Baragar: Can. Metall. Q., 32 (1993), 165.

7) Y. Misaka and T. Yoshimoto: J. Jpn. Soc. Technol. Plast., 8 (1967), 414.

8) S. Shida: J. Jpn. Soc. Technol. Plast., 10 (1969), 610.

9) P. D. Hodgson and D. C. Collinson: Proc. Symp. Mathematical Modeling of Hot Rolling Steel, ed. by S. Yue, CIM, Montreal, (1990), 239

10) J. H. Beynon and C. M. Sellars: ISIJ Int., 32 (1992), No. 3, 359.

11) J. M. Cabrera, A. AL Omar and J. J. Jonas: Metall. Trans. A, A28 (1997), 2233.

12) C. A. Hernandez, S. F. Medina and J. Ruiz: Acta. Mater., 44 (1996), No. 1, 155

13) S. I. Kim, Y. Lee and S. M. Byon: Mater. Proc. Tech., 140 (2003), 84.

14) A. Yanagida and J. Yanagimoto: Mater. Trans., 44 (2003), No. 11, 2303.

15) M. V. K. Chari and Z. J. Csendes: IEEE Trans. Mag., MAG-13 (1977), 1125.

16) T. Nakata, N. Takahashi, K. Fujiwara and Y. Kawase: IEEE Trans. Magn., MAG-24 (1988), 178.

17) D. C. Vallace, P. H. Sidles and C. G. Danielson: J. Appl. Phys., 31 (1960), 168.

18) Thermophysical Properties Hand Book, Youken-do, Tokyo, (1990) 187.

19) K. Ogawa: Magnetic, Tokai Daigaku-Shuppan, Tokyo, (1970), 53.

20) W. J. McG Tegart and A. Gittins: Hot Deformation of Austenite, ed. by J. B. Balance, The Metallurgical Society of AIME, New York, (1977), 1.

21) C. M. Sellars and W. J. McG. Tegart: Mem. Sci. Rev. Met., 63 (1966), 731 . 